Original Research Paper

\title{
Investigating Effects of Application of Silica Fume to Reduce Asphalt Oxidative Aging
}

\author{
${ }^{1}$ Nader Abutalib, ${ }^{1}$ Elham H. Fini, ${ }^{1,2}$ Sassan Aflaki and ${ }^{1}$ Taher M. Abu-Lebdeh \\ ${ }^{I}$ Department of Civil, Architectural and Environmental Engineering, \\ North Carolina A\&T State University, Greensboro, NC, USA \\ ${ }^{2}$ School of Civil Engineering, College of Engineering, University of Tehran, Tehran, Iran
}

Article history

Received: 26-11-2014

Revised: 04-02-2015

Accepted: 8-04-2015

Corresponding Author:

Elham H. Fini

Department of Civil, Architectural and Environmental Engineering,

North Carolina A\&T State

University, Greensboro, NC, USA

Email: efini@ncat.edu

\begin{abstract}
This paper investigates the feasibility of using silica fume to enhance the rheological properties of asphalt binder. It has been widely reported that asphalt binder oxidation is one of the phenomena that reduces the service life of asphalt pavement by negatively impacting its rheological properties. This in turn can lead to a more brittle pavement which is more prone to cracks due to thermal stress and traffic loading. Prior research has shown that introduction of nano-silica to asphalt can reduce asphalt oxidation aging; however, the main challenge with use of nano-silica found to be agglomeration of nano-particles to form micro size clusters which can reduce nano-silica effectiveness while making asphalt binder more susceptible to shear. Therefore, this paper studies effectiveness of using silica fume to reduce asphalt oxidative aging while alleviating agglomeration issue. To do so, various percentages of silica fume was introduced to a base asphalt binders and the rheological properties and high temperature performance of each specimen was evaluated by measuring the rotational viscosity and complex shear modulus before and after oxidative aging. Analysis of the experimental results showed that silica fume reduced asphalt aging index significantly; in addition the temperature susceptibility of asphalt binder was reduced as the percentage of silica fume increased. The flow of modified mixtures increased and the loss of stability of samples decreased as the amount of silica fume increased. The positive effect of silica fume on base asphalt's rheological properties could be attributed to the high surface area and the low degree of agglomeration of the silica fume due to their high polarity. This in turn could improve silica fume's blending properties resulting in a uniformly distributed silica fume modified matrix with enhanced oxidative aging resistance.
\end{abstract}

Keywords: Silica Fume, Aging, Asphalt Binder, Rotational Viscometer

\section{Introduction}

Worldwide annual consumption of asphalt is 150 million tons which makes it an $\$ 80$ billion dollars industry in 2013. In the U.S., generally $90 \%$ of liquid asphalt is used for road paving. It has been well reported that asphalt pavement aging is mainly associated with asphalt binder oxidation at the molecular level. The increased oxidation has been shown to decrease the service life of roads. This phenomenon is known to be expedited at high temperature, accompanied by loss of asphalt volatile compounds. Oxidation affects molecular chains in the pavement, leading to their breakdown as well as creation of new chemical compounds including carbonyl and sulfoxide compounds. These in turn lead to an increase in asphalt binder viscosity while reducing its phase angle as the oxidation progresses resulting in a stiffer and more brittle material (Huang et al., 2012).

Nano-silica has been highly used in the polymer industry to reduce aging and to increase mechanical and physical properties of base materials such as stiffness, toughness, strength and thermal stability (Lee et al., 2005). Recently, there have been studies on the use of various nano-particles to modify asphalt 
binders; for instance, it has been shown that nano-clay can be an effective additive for use in asphalt binder (Onochie et al., 2013). Furthermore, studies reported that the presence of layered silicate Montmorillonite (MMT) nano-clay in asphalt binder can significantly reduce asphalt oxidative aging, provided that intercalation or exfoliation of silicate layers can be achieved. Typically, intercalation or exfoliation has been facilitated using nano-clay modification; a modification that has been reported effective in facilitating exfoliation of silicate layers has been organo-modification of clay particles (Yu et al., 2010). The level of exfoliation has been monitored mainly by measuring the spacing of silicate layers using X-ray diffraction.

Other studies have used nano-silica to achieve a highly polar surface and reported that nano-silica can be very effective in reducing the aging rate while enhancing resistance to rutting and cracking. In fact, modifiers such as silica fume have the capability to enhance the aging resistance of asphalt binder as well as extend the asphalt's high- and low-temperature workability. However, to achieve such improvements, it is critical to ensure uniform blending of nano-silica into the asphalt matrix. Agglomeration of nano-silica particles has been reported to be an issue for such applications (Amirkhanian et al., 2011). Therefore, this study investigates the effectiveness of silica fume in the form of a granulated industrial waste with highly polar surface area to enhance blending and improve asphalt oxidation resistance.

\section{Background}

There have been many studies on investigating the asphalt binder oxidation mechanisms; many researchers tried to develop modifiers and additives to enhance asphalt binders resistance to oxidative aging. Oxidative aging of asphalt binder is expedited when heated at the application temperature and mixed with stone aggregates; this usually is accompanied by significant loss of volatiles compounds while giving rise to carbonyl and sulfoxide compounds in asphalt ( $\mathrm{Lu}$ and Isacsson, 2002). Several researchers used nano-silica to reduce oxidation rate of asphalt; however, nano-silica found to be prone to agglomeration as such this paper investigated feasibility of using silica fume. To the best of authors' knowledge, the use of silica fume to reduce asphalt oxidation has not been fully investigated. This is when micro size particles of silica fume could reduce agglomeration while improving asphalt aging resistance.

It has been reported that approximately 5.11 million tons of silica fume were produced in 2010 and 4.78 million tons in 2012. Since silica fume is a frequently available industrial waste (Haipeng et al., 2014), its application in asphalt paving could facilitate industrial waste management while improving asphalt sustainability and performance. Silica fume is a very fine pozzolanic material with an average particle size of 100-200 nm. It is extracted from gases produced while making silicon or ferrosilicon alloy at $1750^{\circ} \mathrm{C}$. The exhaust dust from the smoke is then collected on electrostatic filters as silica fume (SFA, 2005). Silica fume is made of extremely fine granulated particles that have very high silica content with specific gravity of 2.20. Silica fume is categorized as nano-particles because of the size ranges and particle shape. Due to its polarity and high surface area, it can be used as an additive in asphalt binder to improve the properties of the asphalt binder (Mikoc and Markovic, 2010). Therefore, this paper focuses on using silica fume as an additive to enhance the rheological properties of the asphalt binder.

\section{Materials and Methods}

The asphalt binder used in this study was PG 64-22 and industrial waste silica fume. The silica fume concentrations in asphalt binder were selected to be 2, 4 and $8 \%$, for both aged and non-aged samples. Short-term laboratory aging of the binders was performed using a Rolling Thin Film Oven (RTFO) procedure. The RTFO procedure was executed in accordance with ASTM D 2872-13. The silica fume was acquired through Norchem Company, located in Hauppauge, NY. Table 1 shows the chemical composition of the silica fume used in this study. Silica fume consists of amorphous silica that is produced by electric arc furnaces as a byproduct of the production of elemental silicon or ferro silicon alloys (Gapinski and Scanlon, 2011). The silica fume has 100$200 \mathrm{~nm}$ average particle size (Fig. 4a). A Scanning Electron Microscopy (SEM) image indicates fine particles of silica fume of less than $300 \mathrm{~nm}$ in diameter with surface area ranging from 60,000 to $150,000 \mathrm{ft} 2 / \mathrm{lb}$ and specific gravity of 2.2 (Fig. 1 and 2).

\section{Rheological Characterization}

To study rheological properties of each sample, the Rotational Viscometer (RV) tests were conducted utilizing a Brookfield DV-III Ultra viscometer equipped with thermosel. The basic RV test measures torque required to maintain a constant rotational speed of a specified spindle (in this study, spindle SC27 was used) submerged in liquid asphalt at a constant temperature. The data is then used to calculate viscosity from a measured torque. The viscosity of non-aged samples in the presence of various amounts of silica fume (2, 4 and $8 \%$ ) was measured by viscometer, following the ASTMD4402 specification. Viscosity was measured at four different temperatures $\left(105,120,135\right.$ and $\left.150^{\circ} \mathrm{C}\right)$ and six different speeds $(5,10,20,25,50$ and 75 RPM). At each temperature, the reading was recorded after every $30 \mathrm{~min}$. 
Table 1. The chemical composition of silica fume (Haipeng et al., 2014)

\begin{tabular}{lrll}
\hline Chemical compositions & & Chemical compositions & 0.60 \\
\hline Silicon Dioxido & 90.26 & Sodium Oxide & 1.34 \\
Aluminum Oxide & 0.13 & Potassium Oxide & 0.29 \\
Iron Oxide & 2.46 & Sulfur trioxide & 0.26 \\
Calcium Oxide & 0.29 & Others & 2.80 \\
Magnesium Oxide & 1.57 & Loss on ignition & \\
\hline
\end{tabular}

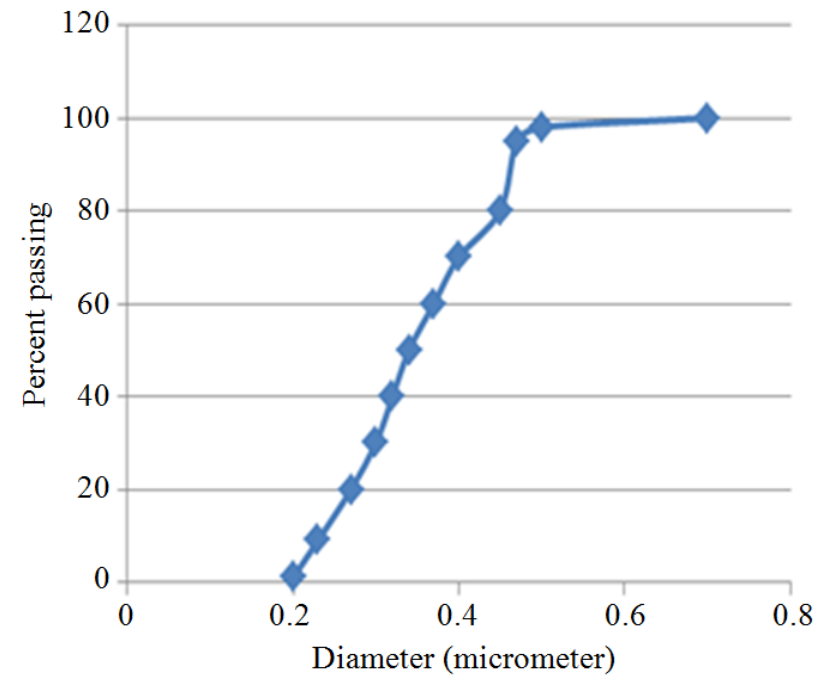

Fig. 1. Silica fume particles size distribution

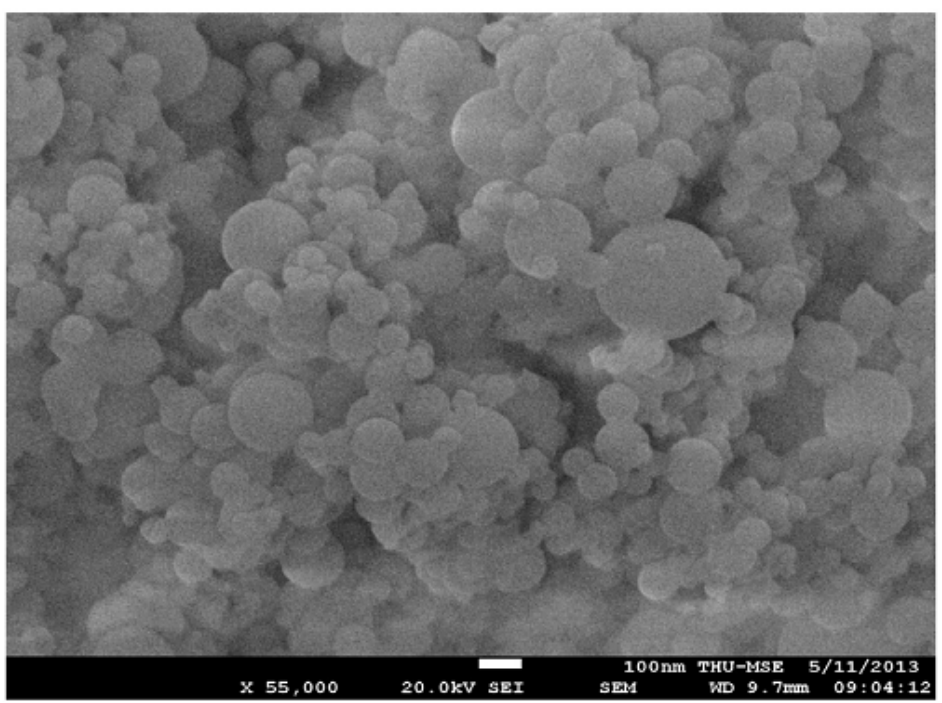

Fig. 2. Silica fume particle shape

\section{Fourier Transform Infrared Spectroscopy (FTIR)}

FTIR analysis was used to characterize silica-fumemodified asphalts. An FTIR spectrometer, Shimadzu 1.30 (2005) single reflection zinc selenide prism, was used in transmission mode. In wave-numbers ranging from $4000 / \mathrm{cm}$ to $500 / \mathrm{cm}$, the test was conducted to get the spectra of asphalt samples. The prism was cleaned with methylene chloride. The frequencies of IR radiation ("peaks" or "signals") could be linked directly to the bond type. Each bond vibrates in different motions (stretching or bending); individual bonds may absorb different IR frequencies. Stretching absorptions usually produce stronger peaks than bending, however, the weak absorptions can be useful in differentiating similar types of bonds (e.g., aromatic substitution). 


\section{X-Ray Diffraction Test}

XRD is a significant technique to examine the exfoliation of nano-particles in asphalt binders. This test is used to demonstrate a material's polycrystalline structure. It identifies components in a sample by search/match procedure. This tool is used to identify the atoms and molecular structure in the crystal. From the density of the electron produced by the crystallographer, the position of the atoms can be calculated, as well as the chemical bonds (Dutrow and Clark, 2013). All samples were placed in an oven at $150^{\circ} \mathrm{C}$ until a homogeneous liquid phase was attained. A small portion was then placed in a silver sample holder (eight $\mathrm{mm}$ each in diameter). Each specimen was carefully examined to identify any bulge or irregularity on the surface. The sample-A glass plate was used to trim any excess sample off the top of the specimen. The sample holder was then placed on a flat surface and the samples were loaded onto the tray. The specimens were left to cure at room temperature before running the test. After curing, the samples were placed on an eight-shelf holster and set in the correct position for testing to take place.

\section{Data Analysis}

The viscosity measurement results indicate a significant increase of viscosity due to the addition of silica fume (Fig. 3a). It can be seen at $105^{\circ} \mathrm{C}$ that with the addition of $2 \%$ silica fume to the control binder, the viscosity increased by $23 \%$, while adding $8 \%$ silica fume increased the viscosity by $56 \%$. At $120^{\circ} \mathrm{C}$, the viscosity increased by $15 \%$ when $2 \%$ silica fume was introduced to the control asphalt binder, while adding 4 and $8 \%$ silica fume increased the viscosity by 34 and $43 \%$, respectively. At $135^{\circ} \mathrm{C}$, which is the standard temperature, a $4 \%$ increase in viscosity was found when $2 \%$ silica fume was introduced to the control asphalt binder. When $4 \%$ silica fume was added to the control binder, the viscosity increased by $24 \%$, while adding $8 \%$ silica fume increased the viscosity by $40 \%$. At a high temperature of $150^{\circ} \mathrm{C}$, the viscosity increased by 18,41 and $55 \%$ when 2,4 and $8 \%$ silica fume was added, respectively.

The Viscosity Aging Index (VAI) is used to evaluate the extent of aging. It is calculated from the viscosity of the samples before and after short-term (RTFO) aging, according to the formula shown in Equation 1. The VAI indicates the extent of age hardening in terms of viscosity (Zhang et al., 2012). The values of VAI for modified and non-modified specimens at $20 \mathrm{rpm}$ are shown in Fig. 3:

$$
V A I=\frac{\eta_{\text {aged }}-\eta_{\text {unaged }}}{\eta_{\text {unaged }}}
$$

Where:

$\eta_{\text {aged }}=$ The viscosity of aged sample (Pa.s)

$\eta_{\text {unaged }}=$ The viscosity of aged sample (Pa.s)

As can be seen in Fig. 4, the VAI values at $20 \mathrm{rpm}$ for silica-fume-modified binders are overall significantly lower than those of control binders. The VIA decreased by $47 \%$ when $2 \%$ silica fume was introduced to the control asphalt binder. With the addition of $4 \%$ silica fume, the VAI decreased by $50 \%$. In the presence of $8 \%$ silica fume, the VAI decreased by $47 \%$. So at $20 \mathrm{rpm}$, the $4 \%$ silica fume sample had the lowest VAI value, 30.51.

\section{Shear Susceptibility}

The Shear Susceptibility (SS) was calculated using the Equation 2. Previous studies showed that binder with relatively small shear susceptibility (low gains in shear susceptibility relative to the increase in viscosity) results in better overall pavement performance (Roberts et al., 1996):

$S S=\frac{\log (\eta)}{\log (\omega)}$

Where:

$\eta=$ The viscosity (Pa.s)

$\omega=$ The speed (RPM)

The shear susceptibility at $120^{\circ} \mathrm{C}$ is indicated in Fig. 5. As can be seen in Fig. 5, the slope was found to be 0.0748 for the control asphalt. The slope reduced to $0.0315,0.0588$ and 0.0476 when 2,4 and $8 \%$ silica fume was introduced, respectively. The shear susceptibility was reduced by 58, 21 and $36 \%$ for the addition of 2,4 and $8 \%$ silica fume, respectively.

\section{Temperature Susceptibility}

Temperature susceptibility is a measurement of ratio of asphalt binder viscosity with temperature change (Claudy and Martin, 1998). Temperature susceptibility WAS calculated using Equation 3 (Rasmussen et al, 2002). The VTS is proportional to the temperature susceptibility of the asphalt binder:

$V T S=\frac{\log \left[\log \left(\eta_{T_{2}}\right)\right]-\log \left[\log \left(\eta_{T_{1}}\right)\right]}{\log \left(T_{2}\right)-\log \left(T_{1}\right)}$

Where:

$T_{1}$ and $T_{2} \quad=$ Are known temperatures in Rankine $\eta_{T_{1}}$ and $\eta_{T_{2}}=$ The viscosities at known temperatures (cP) $(1$ Pa.s $=1000 \mathrm{cP})$ 


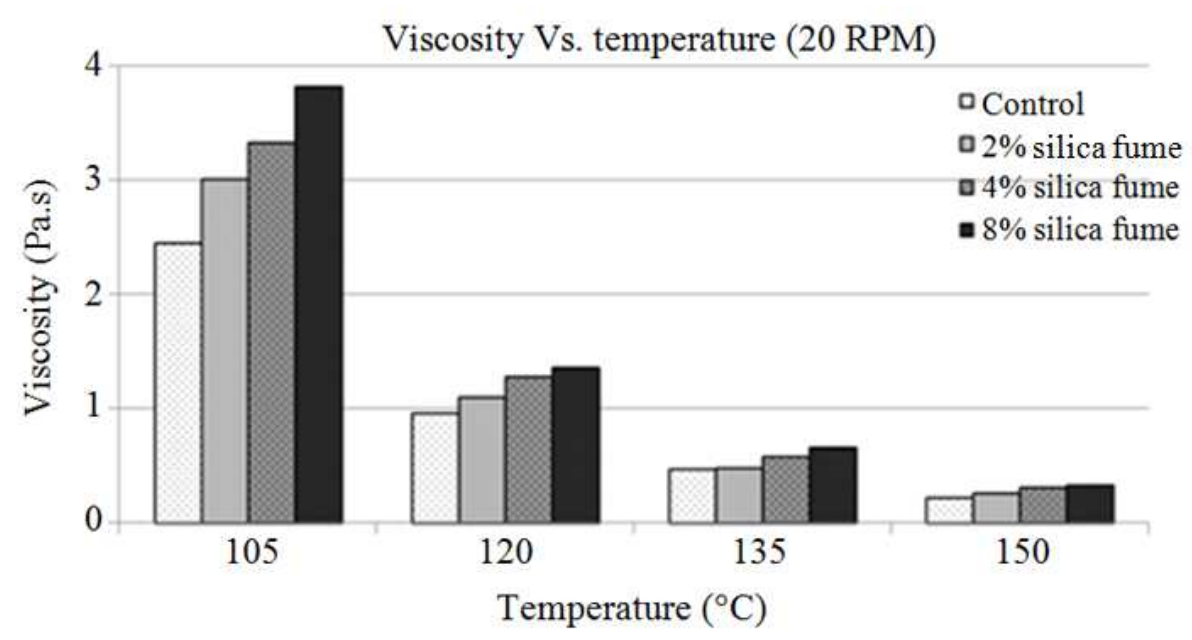

(a)

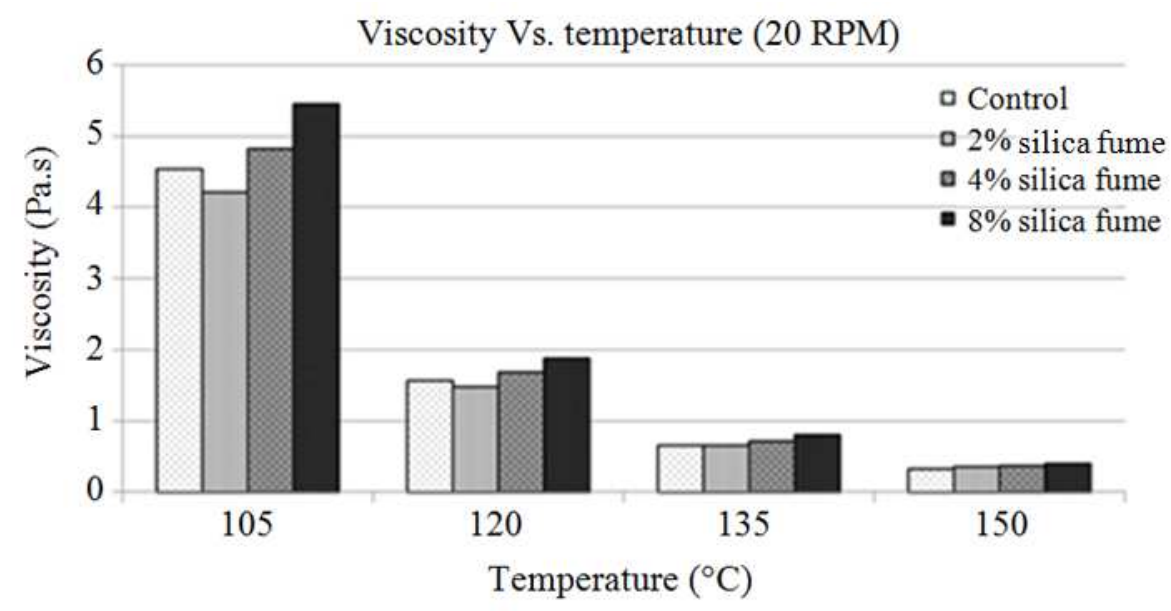

(b)

Fig. 3. Viscosity Vs Temperature at 20 RPM (a) before aging (b) after aging

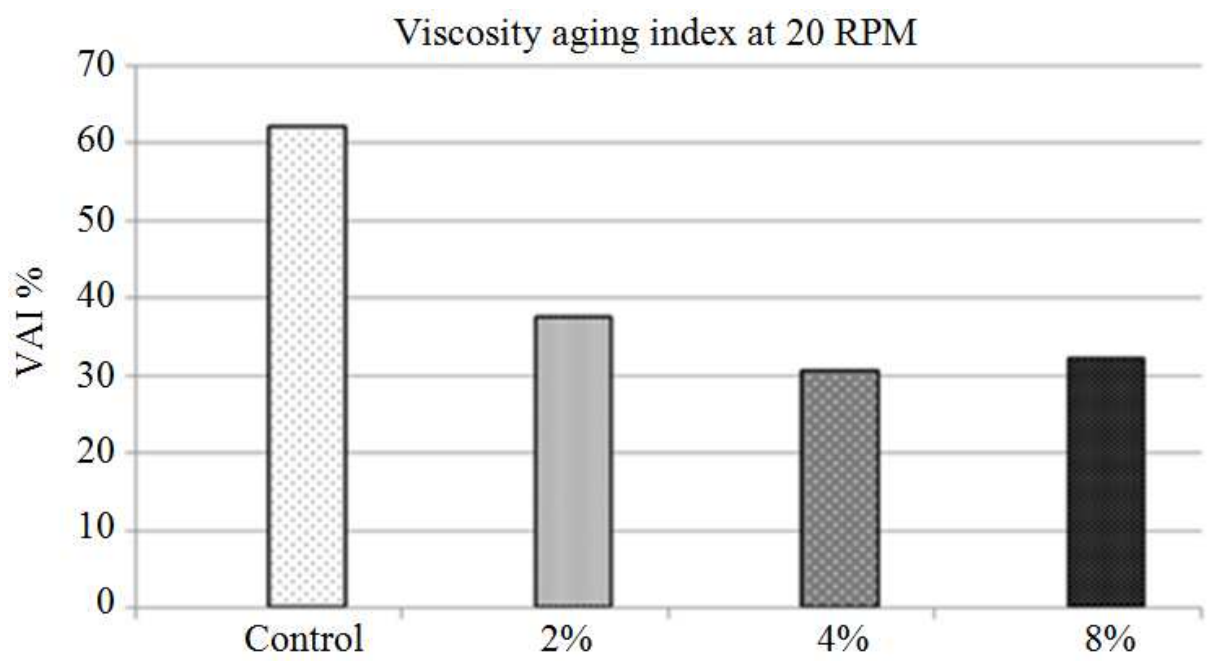

Fig. 4. Viscosity Aging Index of binders after short term aging 


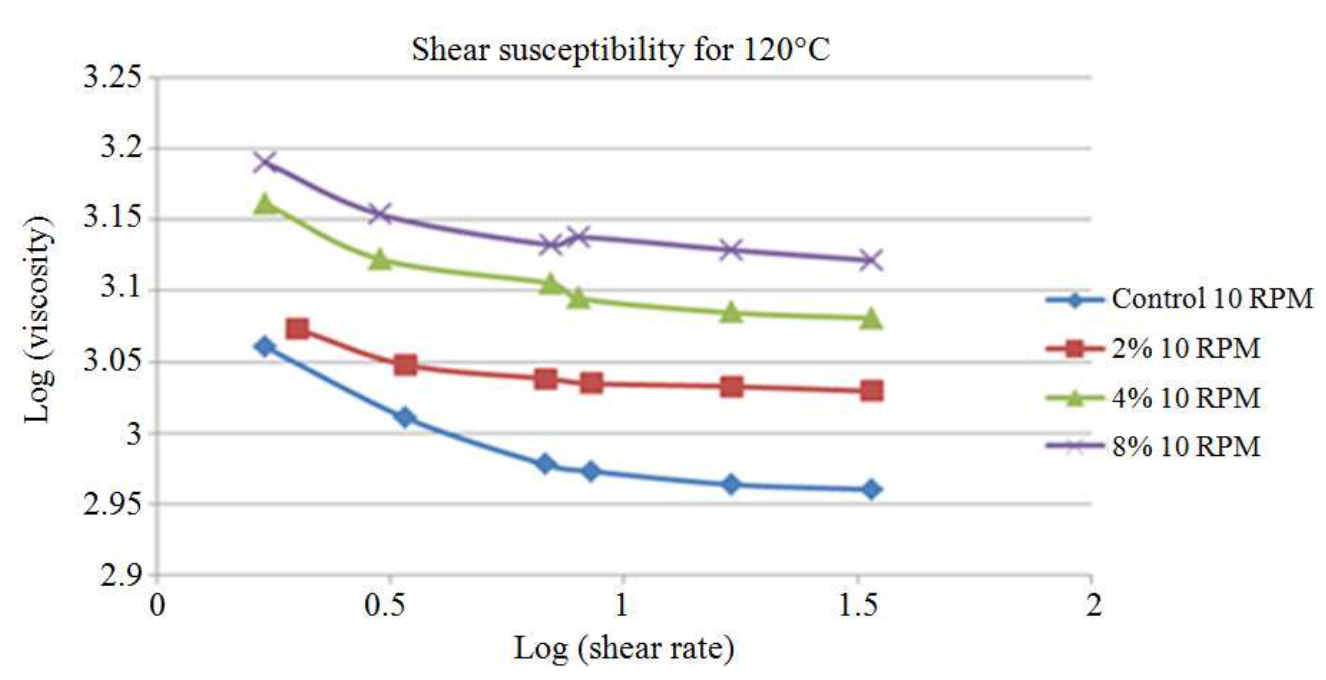

Fig. 5. Shear Susceptibility of samples at $120^{\circ} \mathrm{C}$

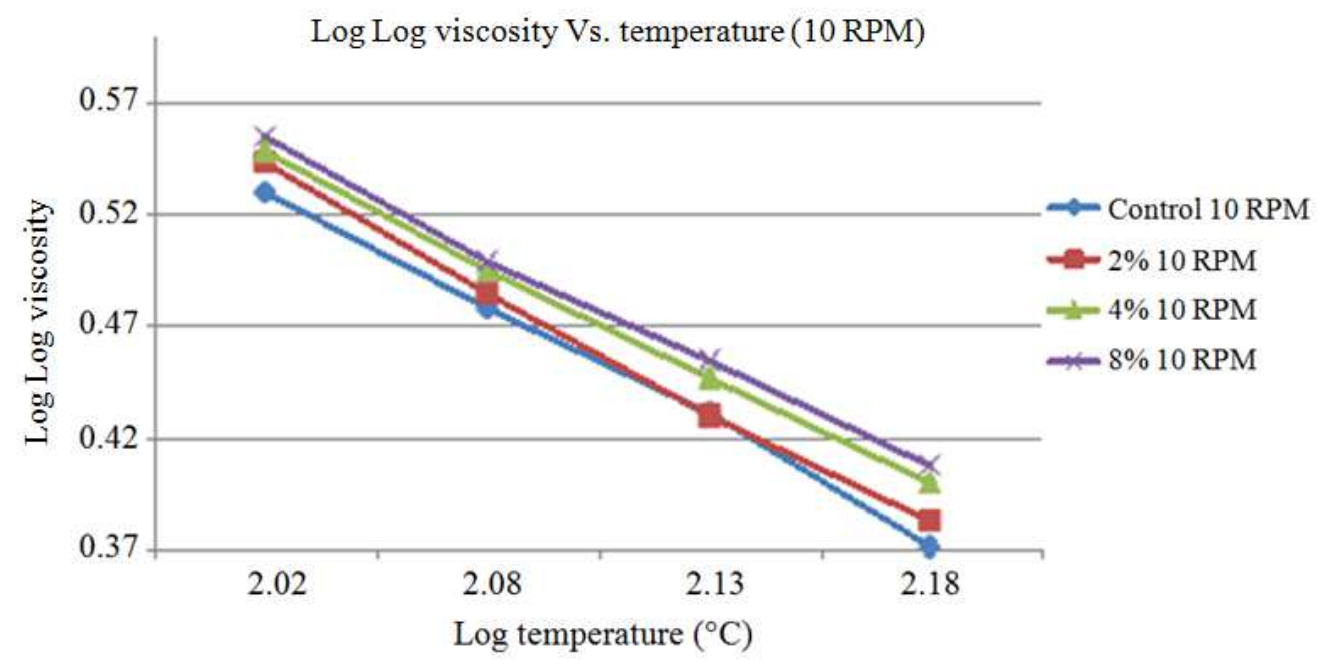

(a)

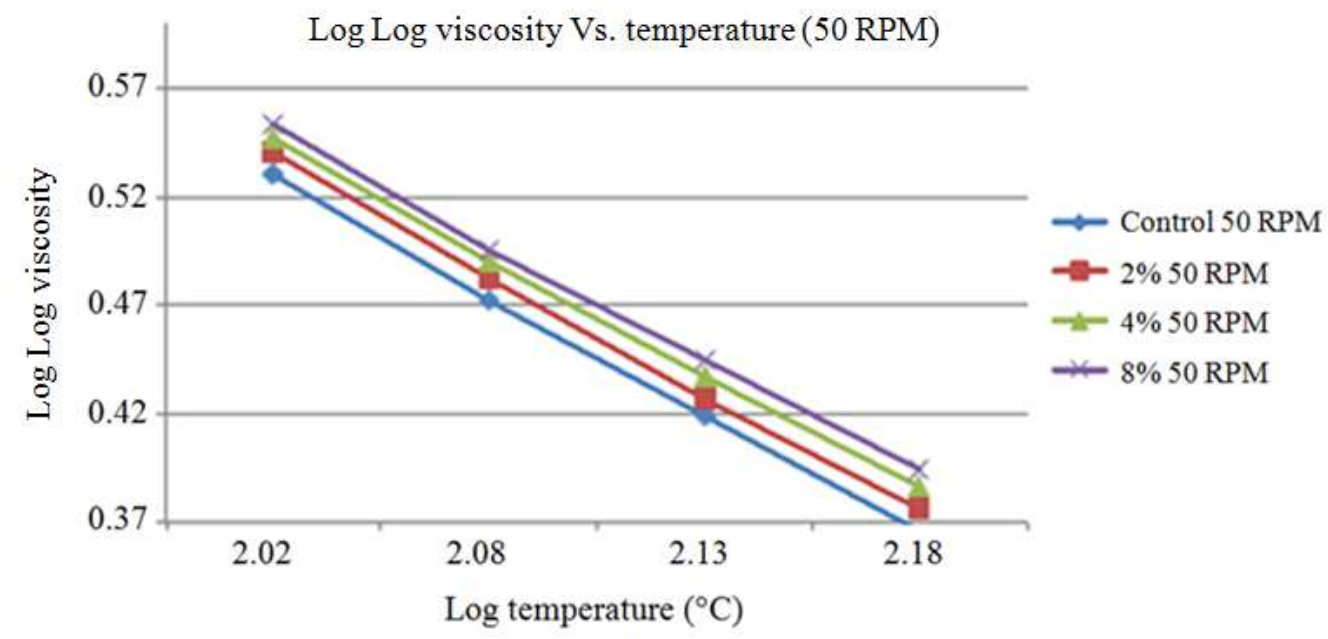

(b)

Fig. 6. Temperature Susceptibility of samples at (a) 10 RPM and (b) 50 RPM 
Figure 6a depicts the ratio of $\log \log$ viscosity versus the temperature at a speed of $10 \mathrm{rpm}$. The slope was found to be 0.0524 for the control asphalt. The slope decreased to $0.0534,0.0492$ and 0.0489 when 2,4 and $8 \%$ silica fume was introduced, respectively.

Figure $6 \mathrm{~b}$ shows the ratio of $\log \log$ viscosity versus the temperature at a speed of $50 \mathrm{rpm}$. In this case, the slope of the control was 0.0545 and it was reduced to 0.0525 when $8 \%$ silica fume was introduced.

\section{Dynamic Shear Rheometer (DSR)}

The complex shear modulus $\left(\mathrm{G}^{*}\right)$ is a measure of total resistance of the binder to deformation when repeatedly sheared and the phase angle is the lag between the applied shear stress and the resulting shear strain. Traditionally, $G^{*} / \sin \delta$ is used to evaluate asphalt binders rutting resistance at high pavement temperatures. At high temperatures, rutting resistance increases as
$\mathrm{G}^{*} / \mathrm{sin} \delta$ increases. The asphalt binder with the higher $\mathrm{G}^{*} / \sin \delta$ suggests a higher resistance to permanent deformation or rutting of asphalt pavement.

Figure 7 shows the complex modulus $\left(G^{*}\right)$ master curves of the aged modified asphalt silica fume composites. It can be seen that the addition of $4 \%$ silica fume to control binder marginally increased the $\mathrm{G}^{*}$ values.

\section{X-ray Diffraction}

Data was collected between the angles of 4 and $60^{\circ} 2$ theta for a two hour period for each sample. All samples were tested on both incident and receiving sides. Test results were used to determine the crystallography of the mixtures being tested in this study. Figure 8 shows silica fume samples at different percentages; no major changes were noticed due to inclusion of silica fume.

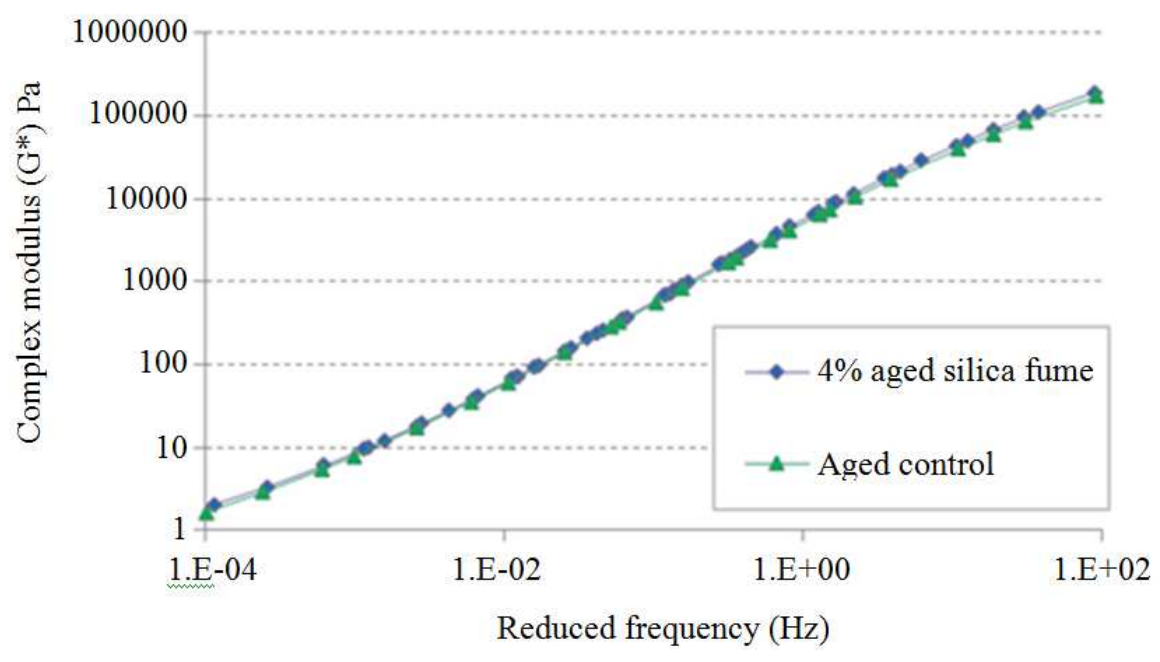

Fig. 7. Complex Shear Modulus Master Curves for aged Samples

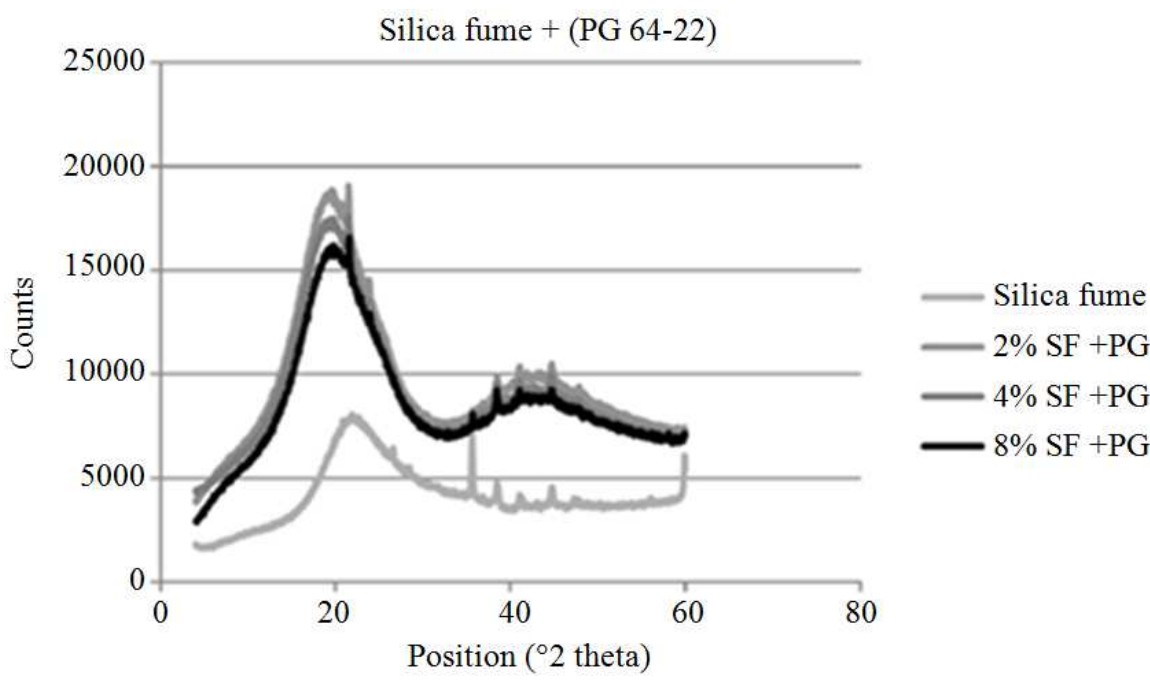

Fig. 8. XRD results of silica fume blended with PG 64-22 


\section{Conclusion}

To reduce the oxidation rate of asphalt binder, silica fume was added to the base asphalt binder PG 64-22 at various percentages. The effectiveness of silica fume in reducing asphalt oxidation aging was evaluated experimentally. Four laboratory tests were conducted: The Marshall test, the X-ray Diffraction (XRD) test, the Fourier Transform Infrared Spectroscopy (FTIR) test and the Rotational Viscosity (RV) test. Marshall tests were conducted to determine the stability and flow. It was shown that adding silica fume reduces loss of stability. The XRD and FTIR tests were used to study the crystalline structure of specimens and their chemical compositions. Study of viscosity results showed that significant increases in viscosity can be obtained by addition of silica fume to the control asphalt binder. Analysis of the experiment results further showed that introduction of silica fume in asphalt binder can significantly reduce its oxidative aging in addition to enhancing stability and flow. The improvement was more noticeable at higher percentages of silica fume, up to $4 \%$. However, above $4 \%$, silica fume appeared to negatively affect the aging index, as measured by a higher aging index at $8 \%$ silica fume. The results of this research are expected to promote pavement service life by reducing oxidative aging while enhancing pavement sustainability and facilitating use of an industrial waste, silica fume.

It was found that $4 \%$ silica-fume-modified binder reduced oxidative aging by $50 \%$, with a relatively low Viscosity Aging Index (VAI) of 30.51. This is in line with the findings of prior research, which showed that introduction of $4 \%$ nano-silica could reduce oxidative aging by $29 \%$ (Onochie et al., 2013). It should be noted that silica fume was even more effective than nano-silica when the same percentages were used and silica fume is currently considered an industrial waste and is frequently available at relatively low cost. Considering that the surface area of nano-silica is much higher than that of silica fume, nano-silica could be expected to be more effective in interacting with asphalt binder. However, the better aging performance of silica fume relative to nano-silica that was observed in this study could be attributed to a reduction in the agglomeration typically observed for nano-silica; agglomeration has been recognized as a problem in dealing with nano-silica. Therefore, the reduced agglomeration in silica fume could be linked to its improved oxidative aging performance.

\section{Acknowledgement}

This research is sponsored by National Science Foundation (awards 1150695), the Laboratory for Atomistic and Molecular Mechanics (LAMM) as well as the Center for Materials Science and Engineering at MIT, a MRSEC supported by NSF award \# DMR-0819762. The contents of this paper reflect the view of the authors, who are responsible for the facts and the accuracy of the data presented. This paper does not constitute a standard, specification, or regulation.

\section{Author's Contributions}

All authors equally contributed in this work.

\section{Ethics}

This article is original and contains unpublished material. The corresponding author confirms that all of the other authors have read and approved the manuscript and no ethical issues involved.

\section{References}

Amirkhanian, A., F. Xiao and S. Amirkanian, 2011. Evaluation of high temperature rheological characteristics of asphalt binder with carbon nano particles. J. Test. Evalu., 39: 583-591. DOI: $10.1520 /$ JTE103133

Claudy, P. and D. Martin, 1998. Thermal behavior of asphalt cements. Thermochemical Act., 324: 203-213. DOI: 10.1016/S0040-6031(98)00537-1

Dutrow, B. and C. Clark, 2013. X-ray Powder Diffraction (XRD). The Science Education Resource Center at Carleton College.

Gapinski, G. and J. Scanlon, 2011. Silica fume. Norchem, Inc.

Haipeng, J., Z. Huang, K. Chen, W. Li and Y. Gao et al., 2014. Synthesis of Si3N4 powder with tunable $\alpha / \beta$ Si3N4 content from waste silica fume using carbothermal reduction nitridation. Powder Technol., 252: 51-55. DOI: 10.1016/j.powtec.2013.10.030

Huang, S., R. Glaser and F. Turner, 2012. Impact of water on asphalt aging: Chemical aging kinetic study. Transport. Res. Record, 2293: 63-72. DOI: $10.3141 / 2293-08$

Lee, L., C. Zeng, X. Cao, X. Han and J. Shen et al., 2005. Polymer nanocomposite foams. Composites Sci. Technol., 65: 2344-2363. DOI: 10.1016/j.compscitech.2005.06.016

Lu, X. and U. Isacsson, 2002. Effect of ageing on bitumen chemistry and rheology. Construct. Build. Mater., 16: 15-22. DOI: 10.1016/S0950-0618(01)00033-2

Mikoc, M. and D. Markovic, 2010. Influence of slag, fly ash and silica fume on the mechanical and physical properties of asphalt. Technical Gazette, 17: 505-514.

Onochie, A., E. Fini, X. Yang, J. Mills-Beale and Z. You, 2013. Rheological characterization of nanoparticle based bio-modified binder. Transportation Research Board of the National Academies. 
Rasmussen, R., L. Robert and C. George, 2002. Method to predict temperature susceptibility of an asphalt binder. J. Mater. Civil Eng., 14: 246-252.

DOI: 10.1061/(ASCE)0899-1561(2002)14:3(246))

Roberts, A., R. Reynolds and K. Verosub, 1996. Environmental magnetic implications of Greigite (Fe3S4) Formation in a 3 m.y. lake sediment record from Butte Valley, northern California. Geophys. Res. Lett., 23: 2859-2862. DOI: 10.1029/96GL02831

SFA, 2005. Silica fume user's manual. Silica Fume Association.
Yu, J., X. Wang, L. Hu and Y. Tao, 2010. Effect of various organomodified montmorillonite/bitumen nanocomposites. J. Mater. Civil Eng., 22: 788-793. DOI: 10.1061/(ASCE)MT.1943-5533.0000012

Zhang, H., J. Yu and S. Wu, 2012. Effect of montmorillonite organic modification on ultraviolet aging properties of SBS modified bitumen. Construct. Build. Mater., 27: 553-559. DOI: 10.1016/j.conbuildmat.2011.07.008 